\title{
Ateísmo moderno y Teología
}

El ateísmo moderno, a partir de mediados del siglo XIX, reviste unas características muy distintas de las del ateísmo anterior, que podríamos llamar ateísmo científico o, como algunos prefieren, ateísmo aristocrático, empeñado como estaba en negar la existencia de Dios a base de argumentos filosóficos. El ateísmo moderno prescinde sencillamente de Dios, lo desarraiga de la historia del mundo, para sumergirse en un humanismo herméticamente cerrado a toda trascendencia. Dios ha sido suplantado por otros absolutos más al alcance de la mano, o simplemente ha sido relegado al olvido más absoluto.

El Concilio Vaticano II menciona brevemente en su Constitución pastoral sobre la Iglesia en el mundo actual las diversas formas del ateísmo moderno, que podríamos glosar dél siguiente modo: el ateísmo positivo, que niega expresamente y sistemáticamente la existencia de Dios; el ateísmo agnóstico que, encerrándose en los límites de lo fenomenológico, es decir, dentro de las fronteras de la experiencia interna y de la experiencia externa o histórica, niega toda posibilidad de conocer a Dios; el ateísmo científico, que pretende responder a todos los interrogantes mediante la investigación científica, sumergida en el evolucionismo más radical; el ateísmo humanista, que prescinde de Dios como de un intruso y se enfrasca de lleno en el hombre mismo, elaborando un humanismo político (ateísmo marxista) o de tipo moral (ateísmo existencialista), y que es la forma de ateísmo más extendida en los tiempos actuales ${ }^{1}$.

1 "La palabra "ateísmo" designa realidadies muy diversas. Unos niegan a Dios expresamente. Otros afirman que nada puede decirse acerca de Dios. Los hay que someten la cuestión teológica a un análisis metódológico tal, que reputan como inútil el propio planteamiento de la cuestión. Muchos, rebasando indebidamente los límites de las ciencias positivas, pretendien explicarlo todo sobre esta base puramente científicia o, por el contrario, rechazan sin excepción toda verdaid: absioluta. Hay quienes exaltan tanto al hombre, que dejan sin contenido la fe en Dios, ya que les interesa más a lo que parece, la afirmación diel hombre que la negación de Dios. Hay quienes imaginan un Dios por ellos rechazado, que nada tiene que ver con el Dios del Evangelio. Otros ni siquiera se plantean la cuestión de la existencia de Dios, porque, al parecer, no sienten inquietud religiosa alguna y no perciben el motivo de preocuparse por el hecho religioso" (Const. past. Gaudium et spes = Sobre la Iglesia en el mundio actual, Madrid, ed. BAC, 1965, 232). Citaremos el número de la Constitución con la sigla BAC seguida de la página correspondiente. 
En estas páginas nos proponemos hacer únicamente algunas consideraciones sobre el ateísmo moderno y la teología cristiana, siguiendo de cerca las directrices del Concilio Vaticano II, que recoge y hace suyas las preocupaciones de muchos teólogos abiertos a los problemas más acuciantes de la humanidad actual. Toda la exposición va ordenada a este fin, sin que pretendamos agotar aquí la problemática filosófica que implican las distintas formas del ateísmo moderno. Nos hallamos ante un hecho aterrador: grandes masas humanas totalmente alejadas de Dios. San Agustín llamaba a esta situación "la grande miseria", porque el hombre vive lejos de Aquel sin el cual no puede existir en modo alguno ${ }^{2}$. Esta muerte espiritual de gran parte de la humanidad es un hecho palpable. El célebre teólogo de Lovaina, G. Philips ha escrito recientemente: "Es un hecho que el hombre moderno, en amplios sectores y un poco en todos los continentes, se ha descubierto como un hombre sin Dios. Ya no tiene necesidad de Dios y lo considera con frecuencia como enemigo. El fenómeno de un ateísmo no sólo vivido, sino proclamado, organizado y militante es un hecho inédito en la historia. Pero es preciso considerarlo de cerca para establecer su verdadero carácter. Son rarísimos los que llegan a prescindir de un absoluto al que referirse. De ahí la profusión de sucedáneos de la religión que se van organizando por todas partes. Culto del deber, de la colectividad, del heroismo sin recompensa, del bienestar social de las generaciones venideras. Esos valores, considerados como obligatorios, ocupan el lugar de un Dios considerado imposible de reconocer en las imágenes corrientes que la representan casi como un ídolo, o como un recurso que llena las lagunas de la actividad humana. Semejante divinidad no supera el orden de las realidades cósmicas" ${ }^{3}$. La trágica realidad del ateísmo moderno y sus profundas repercusiones en los campos religioso, filosófico, científico, político y social del mundo que nos rodea, han hecho de él uno de los problemas más acuciantes y más socorridos de los pensadores cristianos. De aquí que la teología y la filosofía, al contacto con la vida y con la mentalidad del mundo actual, hayan dado un viraje casi en redondo, muy oportuno y necesario, pero también muy doloroso para los que siguen encasillados en unos moldes tan tradicionales y seguros como ininteligibles e ineficaces para el hombre de hoy. El Concilio Vaticano II subraya esta nueva toma de conciencia cuando dice que este ateísmo es "uno de los fenómenos más graves de nuestro tiempo. $\mathrm{Y}$ debe ser examinado con toda atención" ${ }^{4}$. La inmensa bibliografía de estos últimos años nos indica

2. "Magna itaque hominis miseria est cum illo non esise, sine quo non potest esse. In quo enim est, procul dubio sine illo non esit: et tamen si eius non meminit, eumque non intelligit, nec diligit, cum illo non est" (De Trin. XIV, 12, 16, PL. 42, 1.049; Confes. V, 2, 2, PL. 32, 707). 1965) 14

3 G. PHrlips, "La Iglesia en el mundo de hoy": Concilium n. 6 (junio "

4 Const. past. Gaudium et spes..., 19, BAC, 231-232. 
que el Concilio se ha hecho eco de una viva preocupación ya existente entre muchos pensadores cristianos ${ }^{5}$.

Todos los autores se esfuerzan por descubrir las causas que han provocado ese ateísmo tan radical, y tratan de comprenderlo tanto en su negación de Dios como en sus aspectos positivos, para buscar de algún modo su flanco débil que permita entablar con él un diálogo religioso. Ya en el Congreso de Estudios filosóficos para profesores universitarios de Gallarate (1961) se llegó a la conclusión de que el ateísmo moderno tiene su origen en un sinnúmero de causas: el carácter misterioso y velado de nuestro conocimiento de Dios; el concepto de Dios, difícilmente aceptable; la confianza exclusiva del hombre moderno en sí mismo; el considerar como inauténtica la visión religiosa de la realidad; causas vitales y existenciales de tipo social, político y económico muy opuestas a la religión; réplica al ateismo práctico de una parte del mundo cristiano; la sensibilidad ante el problema del mal y el problema enigmático, misterioso y doloroso de la historia. También el Concilio Vaticano II enumera entre las causas del ateísmo moderno el problema del mal, el materialismo creciente y el mal ejemplo de muchos cristianos: "Además, el ateísmo nace a veces como violenta protesta contra la existencia del mal en el mundo o como adjudicación indebida del carácter absoluto a ciertos bienes humanos que son considerados prácticamente como sucedáneos de Dios. La misma civilización actual, no en sí misma, pero sí por su sobrecarga de apego a la tierra, puede dificultar en gradó notable el acceso del hombre a Dios... Sin embargo, también los creyentes tienen en esto su parte de responsabilidad. Porque el ateísmo, considerado en su total integridad, no es un fenómeno espontáneo (originario), sino derivado de varias causas, entre las que se debe contar también la reacción crítica contra las religiones $\mathrm{y}$, ciertamente, en algunas zonas del mundo, sobre todo contra la religión cristiana. Por lo cual, en esta génesis del ateísmo pueden tener parte no pequeña los propios creyentes, en cuanto que, con el descuido de la educación religiosa, o con la exposición inadecuada de la doctrina o incluso con los defectos de su vida religiosa, moral y social, han velado más bien que revelado el genuino

5 Pueden verse, entre otros, losi siguientes estudios: H. de Lubac, $E l$ drama del humanismo ateo, Madrid 1949; H. U. von BALTHASAR, El problema de Dios en el hombre actual, Madrid 1960; M. REDING, Der pólistische Atheismus, Graz, 2. ${ }^{a}$ ed., 1960; Il problema dell'ateismo (Atti del XVI Convegno del Centro di Studi Filosofici fra professori universitari, Gallarate, 1961), Morceliana, Brescia 1962, 482; R. KWANT, "Il marsismo di Sartre": Augustinianum 1 (1961) 94-119, 237-263; ID. "La filosofía di Maurice Merleau-Ponty": Augustinianum 1 (1961) 504-532; B. WELTE, El atersmo de Nietszche y el cristianismo, Madrid 1962; C. FABro, "Le fondement théorique de l'athéisme contemporaine": Sciences ecclesiastiques 14 (1962) 351-374; G. WETTER, Le materialisme dialectique, Bruges 1962, 661; G. di GRAZIA, Ateismo filosofico e esistenza di Dio nel pensiero filosofico e secondo il senso comune, Napoli 1964, 265; J. Y. CALVEZ, El pensamiento de Carlos Marx, Madrid, 4. ${ }^{\text {a }}$ ed., 1964; J. B. METz, "La incredulidad como problema teológico": Concilium n. 6 (junio 1965) 63-83. 
rostro de Dios y de la religión" ${ }^{6}$. Esta constatación del Concilio es un toque de alarma, una llamada de alerta a la responsabilidad de los cristianos ante el fenómeno acuciante del ateísmo moderno.

Aquí nos interesa analizar brevemente las dos corrientes más fuertes del ateísmo contemporáneo, la marxista y la existencialista, para examinar después lo que tienen de positivo y la postura que puede adoptar la teología cristiana ante ese humanismo que prescinde de Dios como de un ídolo intruso en la historia de la humanidad. Dejemos, pues, de lado el ateísmo propuesto bajo la forma de un humanismo científico, al cual va dirigido principalmente el mensaje de trascendencia del P. Teilhard de Chardin ?. Puede verse un análisis breve, claro y profundo del ateísmo moderno en la obra de Jean Lacroix, El sentido del ateísmo moderno. Herder. Barcelona, 1964, p. 126.

\section{El ATEÍSmo MARXista (hUMANismo pOLÍtico).}

El idealismo alemán con sus absolutos apriorísticos e imaginarios, llevado a la exacerbación en el absoluto ideado por Hegel, en perpetuo devenir, en el que el Yo absoluto se identifica de hecho con el Yo humano, choca en su interpretación de la historia con las realidades económicas nuevas y con las tragedias que comienzan a surgir por doquier ante el agudizarse de las diferencias de clases. Hegel nos ofrece un ateísmo larvado, como consecuencia lógica de su idealismo inmanentista. Feuerbach (1804-1872) se enfrenta con este idealismo, acusándolo de reducir el mundo real a un mero concepto abstracto de la mente humana. El invierte este orden al afirmar que es el pensamiento abstracto el que debe ser reducido a la misma cosa pensada, puesto que las ideas no tienen significación alguna a no ser en relación con las cosas concretas, sensibles y materiales. Al enfrentarse con el fenómeno religioso, nos dirá que la idea de Dios no es más que un concepto abstracto, una noción cuya realidad se identifica de hecho con las perfecciones y cualidades de la esencia humana. Basándose en estas perfecciones, la mente humana forma la noción de Dios, la coloca fuera de sí y la reviste de un carácter personal: "Wie Gott nichts Anderes ist als das Wesen des Menschen, gereinigt von dem, was dem menschlichen Individuum... als Schranke, als Übel erscheint: so ist das Jenseits nichts Anderes als das Diesseits, befreit von dem, was als Schranke, als Übel erscheint" ${ }^{8}$. De este modo, Dios

6 Const. past. Gaudium et spes..., 19, BAC, 232-233.

7 Cfr. P. ChauchaRd, El ser humano según Teilhard de Chardin, Herder, Barcelona 1965, 229; A. LocATELLI, Dio e il miracolo conoscibili aĺ di lá della. " scienza, Hildephonsiana 4, Venegono Inferiore (Varese) 1963, 325; cfr. 118-129.

8 L. FeUERBACH, Das Wesen dies Christentums (1841), Stuttgart 1903, 219. 
sería una mera ilusión de la mente humana, un efecto de su necesidad psicológica. El hombre coloca sus ansiedades, sus deseos y sus esperanzas en un mundo más elevado, al que llama Dios, y lo adora.

Esta ilusión es superada por la filosofía, que devuelve al hombre a su realidad terrestre. Si el hombre se considera a sí mismo no como individuo, sino como hombre-especie, entonces se basta a sí mismo. Por eso Feuerbach exalta la vida social como un medio de perfección, puesto que por ella el amor del hombre pasa de Dios a los hombres ${ }^{9}$. Este idealismo materialista no deja de tener su parte positiva por el hecho mismo de considerar el amor mutuo de los hombres como una especie de teofanía, si bien el Dios de esta teofanía sea meramente un producto de la psicología humana. A este respecto, no podemos menos de hacer nuestras, ya desde ahora, las recientes consideraciones del célebre teólogo H. U. von Balthasar: "Es humillante para nosotros los cristianos que haya sido un ateo, Ludwig Feuerbach (Das Wesen des Cbristentums, 1841) el primer filósofo que, después del hundimiento de la gran sistematización occidental, ha llamado la atención sobre el desnudo hecho cristiano. Si bien es verdad que, apenas descubierto, no llegó a comprenderlo, ignorándolo después en absoluto. Mas a él le corresponde el mérito de haber reintegrado la absolutización hegeliana de la idea de Dios en una relación personal entre un Yo y un Tú, como implicación y expresión de aquella. Solamente entonces resplandece Dios, aunque para. Feuerbach este Dios no es otra cosa que el milagro incomprensible del amor personal humano. Nosotros los cristianos hemos de abrir nuestros ojos para ver cómo otros, no cristianos, se encuentran subyugados ante este prodigio y se rinden a sus leyes e implicaciones sin comprenderlo; más aún, en audaz y paradójica contradicción con lo que desde el punto de vista de la filosofía puede parecerles evidente respecto al mundo y al hombre. Entonces hemos de reconocer también la libre actuación de la gracia de Cristo más allá del ámbito de la fe explícitamente cristiana. $\mathrm{Y}$ hemos de admitir, avergonzados, que otros, quizá ateos, puedan presentar ante nuestros ojos la realización de una entrega más auténtica. Esta humillación pertenece esencialmente a nuestro kerigma, ya que de este modo aparecerá siempre claramente ante nosotros mismos y ante el mundo la distinción entre la "Cabeza" y los "miembros", entre el único Salvador y sus deficientes seguidores" 10.

Por lo tanto Feuerbach convierte la teología en antropología y propone un ateísmo que reviste la forma de un humanismo social.

Carlos Marx (1818-1883) depende de Feuerbach en su materialismo, pero lo critica muy duramente por consideratlo aún demasiado especulativo y abstracto

9 L. FEuerbach, O. c., 236.

10. H. U. von BALTHASAR, "El encuentro con Dios en el mundo actual": Concilium n. ${ }^{\circ} 6$ (junio 1965) 39-40. 
al hablar de la esencia del hombre, del hombre-especie, y no del hombre concreto ${ }^{11}$. Marx, con su doctrina comunista, irá a refugiarse en un humanismo político esencialmente ateo. Comienza por considerar la sabiduría como una pura ilusión, otorgando una primacía total y absoluta a la acción. Y en esto radica precisamente el punto de su ruptura con Hegel. "Heredero de los filósofos clásicos, Hegel estima aún que el hombre puede encontrar la satisfacción en la sabiduría, a la que él identifica con el saber absoluto. El hombre, separado primero, se reconcilia con la naturaleza cuando la ha comprendido. En cambio, para Marx el hombre no puede satisfacerse más que en la transformación efectiva del mundo. No hay para él otro plano que el de la praxis. La sabiduría no es exterior a historia, y la noción de una cultura desprendida y exterior a los hechos históricos coincide con la noción de una cultura ineficaz e inútil. En este sentido, y precisamente porque quiere estar presente en el acontecimiento, acaso no fuera falso definir una parte del ateísmo moderno como la negación de toda sabiduría, considerada como ilusoria" 12 .

Esta actitud es esencial en el marxismo y lo lleva necesariamente a la negación de todo teísmo, de todos los espiritualismos y religiones, que para él son un puro idealismo y una alienacion fatal del hombre real y croncreto. El hombre, martirizado y angustiado por las condiciones económicas inhumanas, sufre una contradicción o disociación interna que lo hace olvidarse de su dignidad propia para colocarla fuera de sí y adorarla como a una divinidad. Y esta alienación fatal, origen de toda religión, hace que ésta sea "el opio del pueblo". Así dice Marx: "La miseria religiosa es, por una parte, la expresión de la miseria real y, por otra parte, la protesta contra la miseria real. La religión es el suspiro de la criatura agobiada por la desgracia, el alma de un mundo sin corazón, del mismo modo que es el espíritu de una época sin espíritu. Es un opio para el pueblo" ${ }^{13}$. De este modo para Marx la religión tiene su origen en la alienación económica, en la angustia y agobio del hombre ante la miseria real. Y el culpable de esta alienación es el capitalismo, que considera al dinero como el único valor de todas las cosas; el dinero suplanta así al hombre y es adorado como una divinidad. El Dios de los Hebreos (el oro) es revestido de una forma terrena y adorado por el orbe entero. Engels nos dirá que la religión es el acto por el cual el hombre se vacía de sí mismo y transfiere la esencia de su humanidad al fantasma de un Dios en el más allá.

11 Cfr. F. GRegoire, Aux sources de la pensée de Marx: Hegel, Feuerbach (Bibliotheque Philosophique die Louvain), Louvain 1947, 204. 1964,33

$12 \mathrm{Cfr}$. J. LACRoIx, El sentido del atieńsmo moderno, Herder, Barcelona

13 K. MARX, Contribution a lo critique de la philosophie du droit die Hegrel. Ouvres completes de K. Marx, trad. Molitor, Ouvresi philos., I, 84. Cfr. toda esta problemática en J. Y. CaLvez, El pensamiento de Carlos Marx, Taurus, Madrid. 1964, 57-112. 
El ateísmo marxista, en su aspecto positivo, se reduce a la afirmación o reconquista de la humanidad directa y concreta del hombre sin mixtificaciones idealistas. Es más bien una superación del ateísmo, considerándolo únicamente como una condición previa para partir positivamente del hombre real y concreto, que ha de resolver por sí mismo todos sus problemas, sin acudir para ello a divinidades que en su concepto no pueden existir. Es un ateísmo de desarraigo, fundado en la teoría de la alienación. Sencillamente prescinde de todo espiritualismo, para centrarse en el hombre, causa, artífice y fin de sí mismo. De ahí la crítica durísima que Marx hace de la moral y de los principios sociales del cristianismo, según él, causa de las injusticias, de la inhumanidad y de la inautenticidad existentes: "Los principios sociales del cristianismo han justificado la esclavitud clásica, han glorificado la servidumbre medieval, y cuando hace falta, saben aprobar la opresión del proletariado, aunque con un aire un poco contrito. Los principios sociales del cristianismo predican la necesidad de una clase dominante y de una clase dominada, y para esta última se contenta con formular piadosamente el deseo de que la primera sea caritativa. Los principios sociales del cristianismo trasladan al cielo la compensación... de todas las infamias, y justifican de este modo la perpetuación de esas infamias sobre la tierra. Los principios sociales del cristianismo declaran que todas las infamias cometidas por los opresores contra los oprimidos son el justo castigo del pecado original o de otros pecados, o bien que son pruebas impuestas por el Señor, en su infinita sabiduría, a las almas salvadas. Los principios sociales del cristianismo predican la cobardía, el desprecio a sí mismo, el rebajamiento, la sumisión, la humildad; en resumen, todas las propiedades de la canallería. El proletariado que no se deja tratar como canallà necesita mucho más su valor, su respeto a sí mismo, su orgullo y su amor a la independencia, que no su pan. Los principios sociales del cristianismo son solapados, y el proletariado es revolucionario" 14. Con esta caricatura, que confunde la conducta de muchos cristianos desaprensivos con los principios sociales del cristianismo y que ridiculiza los datos más sagrados de la revelación divina, no es de extrañar que la religión cristiana haya sido la víctima más apetecida del comunismo.

El ateísmo de Marx está basado en definitiva sobre su concepto del trabajo. El hombre es un ser esencialmente obrero, que conquista su humanidad transformando el mundo, sin necesidad de mediador alguno divino que implicaría la negación de la libertad humana. Por eso nos dirá que "La crítica de la religión conduce a la doctrina de que el hombre es para el hombre el ser supremo" 15 . Marx vincula así indisolublemente el problema religioso con la economía y la

14 Deutsche Brüsseler Zeitung, 12 sept. 1874, ed. Mega, I, 6, 271. Cflr. J. Y. Calvez, O. c., 88.

15 Contribution a la critique..., cit., 97. 
política, no dudando en afirmar que "la historia tiene la misión, una vez desvanecida la vida futura de la verdad, de establecer la verdad de la vida presente. Y la primera tarea de la filosofía, que está al servicio de la historia, consiste, una vez desenmascarada la imagen santa que representaba la renuncia del hombre a sí mismo, en desenmascarar esta renuncia en sus formas profanas. La crítica del cielo se transforma así en crítica de la tierra; la crítica de la religión, en crítica del derecho, y la crítica de la teología, en crítica de la política" ${ }^{16}$. Suprimiendo la propiedad privada, que separa a unos hombres de otros por la diferencia de clases, elimina asimismo a Dios, que separa al hombre de sí mismo. Es decir, que "el ateísmo es el humanismo mediatizado por la supresión de la religión, y el comunismo es el humanismo mediatizado por la supresión de la propiedad privada" ${ }^{17}$.

Esta doctrina marxista, llevada por Lenin hasta sus últimas consecuencias sociales, parece que no conserva hoy día en Rusia la pureza de su materialismo dialéctico. El P. G. Wetter llega a la conclusión de que apenas hay dialéctica propiamente tal en la filosofía soviética actual. Esta filosofía se limita más bien a exponer un evolucionismo naturalista revestido de terminología dialéctica ${ }^{18}$. $\mathrm{Y}$ esta obra del P. Wetter no puede ser tachada de inobjetiva, porque los mismos estudiantes de la Universidad de Moscú, que conocen al alemán, han preparado por ella su examen de materialismo dialéctico.

Resumiendo, podemos decir que la filosofía marxista considera el ateísmo como algo dado, como una condición previa para construir el humanismo político. El Concilio Vaticano II lo resume así en pocas palabras: "Entre las formas del ateísmo moderno debe mencionarse la que pone la liberación del hombre principalmente en su liberación económica y social. Pretende este ateísmo que la religión, por su propia naturaleza, es un obstáculo para esta liberación, porque, al orientar el espíritu humano hacia una vida futura ilusoria, apartaría al hombre del esfuerzo por levantar la ciudad temporal. Por eso, cuando los defensores de esta doctrina logran alcanzar el dominio político del Estado, atacan violentamente a la religión, difundiendo el ateísmo, sobre todo en materia educativa, con el uso de todos los medios de presión que tiene a su alcance el poder público" 19.

16 Ibid., 85

Citado por J. LaCRoIX, O. c., 39.

18 G. A. WETTER, Le materialisme dialectique, Bruges: 1962, 661; G. A. WeTter - W. Leonhard, La ideología soviética, Hemder, Barcelona 1964, 676.

19: Const. past. Gaudium et spes..., 20, BAC, 234. 


\section{II. ËL ATEÍSMo eXISTENCIALISTA (HUMANISMO MORAL).}

El Concilio Vaticano II, hablando del ateísmo sistemático, compendia en estas palabras el de carácter existencialista: "Con frecuencia, el ateísmo moderno reviste también la forma sistemática, la cual, dejando ahora otras causas, lleva al afán de autonomía humana hasta negar toda dependencia del hombre respecto de Dios. Los que profesan este ateísmo afirman que la esencia de la libertad consiste en que el hombre es el fin de sí mismo, el único artífice y creador de su propia historia. Lo cual no puede conciliarse, según ellos, con el reconocimiento del Señor, autor y fin de todo, o por lo menos tal afirmación de Dios es completamente superflua. El sentido de poder que el progreso técnico actual da al hombre puede favorecer esta doctrina" 20.

Es sabido de todos que bajo el nombre de filosofía existencialista se cobijan las tendenciąs más opuestas en lo que al problema de Dios se refiere: ateos, teístas, cristianos.

En general, el existencialismo suele definirse como "la filosofía de la existencia personal del hombre, sintetizada en la libre elección del propio destino" ${ }^{21}$. Es una reacción o lucha contra la filosofía perenne, desde Platón a Leibniz (†1716), que es una filosofía de la esencia abstracta, para centrarse en una filosofía de la existencia de la persona humana por introspección inmediata; es decir: el filósofo existencialista debe dedicar sus esfuerzos a desvelar las estructuras de la propia conciencia mediante el análisis fenomenológico. En esta filosofía la esencia del hombre no es algo abstracto, metafísico, sino algo que debe ir haciéndose a lo largo del drama de la propia vida. Asimismo, la personalidad irá formándose por la elección libre del propio destino.

El instaurador del existencialismo moderno, Soren Kierkegaard (1813-1855), era profundamente cristiano. La catástrofe familiar, - su padre maldijo de Dios y se casó con su criada antes de que muriera su primera esposa-, influyó definitivamente en su inquietud religiosa y en su filosofía trascendente. El ilustre teólogo calvinista Karl Barth comenzará exaltándolo, pero, al percatarse de la crítica durísima que hace del protestantismo, terminará combatiendo su postura. El P. C. Fabro, traductor de las obras de Kierkegaard al italiano, dice que el filósofo danés ha servido de estímulo para que muchas almas protestantes buscaran y hallaran el catolicismo en el cristianismo primitivo del Nuevo Testamento ${ }^{22}$. Pero la terminología existencial de Kierkegaard, angustia, culpa, fe,

20 Ibid., 20, BAC, 233-234.

21 Cfr. F. J. Thonnard, Precis d'histoire de la philosophie, Desclée, ParísTournai-Rome, $2 .{ }^{a}$ ed., $1948,885$.

22 C. FABR0, Arbor (mayo 1949) 114; ID. S. Agostino e l'esistenzialismo, S. Agostino e le grandi correnti della filosofia contemporanea (Atti del Congresso 
decisión, elección, ha sido vaciada de su sentido trascendente por otros existencialistas ateos, como Jean Paul Sartre, Polin, Merleau-Ponty y de hecho también por M. Heidegger.

J. P. Sartre, después de varios ensayos literarios, sistematizó su pensamiento en su obra fundamental L'Etre et le Néant. Essai d'ontologie phénoménologique (París, 1943, p. 724) ${ }^{23}$. Según él, el ateísmo es un supuesto dado del existencialismo, y llega a afirmar que "el existencialismo no es más que un esfuerzo para sacar todas las consecuencias de una posición atea coherente" ${ }^{24}$. Sartre ha ido suavizando un poco su postura en pro de un cierto socialismo, porque la doctrina de su obra fundamental era desesperante. La existencia humana no tenía explicación alguna. El hombre es un "ser arrojado ahí", condenado a la libertad, es decir, a elegir un destino, sabiendo ya de antemano que no le conducirá a nada. El sentimiento que mejor revela la existencia humana es la náusea, el tedio, la angustia de la vida, que no tiene más sentido que la muerte.

En su obra fundamental hace un análisis, que podríamos llamar metafísico, de su postura nihilista. La objetividad, las cosas, la materia (en-soi) está abí, es algo bruto, idéntico a sí mismo, contingencia absoluta, sin explicación de ningún género. Por otra parte, la conciencia (pour-soi), la otra realidad opuesta al en-sí, al ser simplemente, que no es una sustancia sino más bien una apariencia, porque no existe sino en la medida en que aparece, nos enfrenta irremediablemente con la nada, bien porque la respuesta a lo que se pregunta sea negativa (esto no existe), o bien porque la respuesta afirmativa supone ya una limitación: al decir que una cosa es, que algo es así, excluímos de nuestra afirmación todo lo demás que "no es así", es decir, nos encontramos también envueltos en la nada. Para Sartre, la nada anida siempre, traída por la conciencia, en el seno mismo del ser: "La nada, si no está sostenida por el ser, se disipa en cuanto nada y volvemos a caer en el ser. La nada no se "nadifica", sino sobre el fondo del ser; si puede darse la nada, no es ni antes ni después del ser, ni de una manera general fuera del ser, sino que está en el seno mismo del ser, en su corazón, como un gusano" ${ }^{25}$. La otra realidad, la tercera, son los otros, que son otras tantas conciencias: En esta y en otras obras de esos años, el contacto con los otros y los sentimientos de defraudación que nos causan, le hicieron llegar a decir: "El in-

Italiano di Filosiofia Agostiniana. Roma, 20-23 ott. 1954), Tolentino 1956, 141166 ; cfr. 156-166.

23 Cfr. R. KWaNT, O. S. A., "Il marsismo di Sartre": Augustinianum 1 (1961) 94-119; 327-363, con la bibliografía más importante; R. TRoIsFonTAINES, El existencialismo ateo de J. P. Sartre, Introd., trad. y notas die J. Sáinz Mazpule, Marfil, Alcoy 1949, 190.

24 L'existentialisme est un humanisme, conferencia de Sartre en 1946, en la que suaviza la tesis de $L$ tre et le neant, proponiendo una moral más humana*, debido a las contingencias sociales.

25 L'etre et le neant, 57. 
fierno son los otros". Posteriormente dulcificó esta dureza, fundándose en las contingencias sociales.

1 Su filosofía le lleva además a una moral sin pecado. El ateísmo debe desarraigar del hombre el sentimiento de culpabilidad, de pecado, reivindicando la inocencia de la condición humana. Su única responsabilidad será externa, ante los demás, ante la historia. Dios es inútil; sólo interesan yo, los otros y el mundo ${ }^{26}$.

M. Merleau-Ponty defiende este mismo ateísmo o humanismo moral, si bien de un modo más intelectualista. La antropología vuelve a poner el destino del hombre en sus manos. La hipótesis Dios debe ser descartada, porque no es más que un obstáculo para comprender el sentido inmanente de los aconteci. mientos interhumanos. La humanidad misma tiene la responsabilidad total de su destino, que ella misma irá forjándose libremente ${ }^{27}$.

Sartre ha sido sin duda el que mayor influjo ha tenido en el gran público con sus innumerables publicaciones de todo género. En el París de la posguerra había grupos de jóvenes que trataban de vivir ese existencialismo ateo y desesperante traducido al estilo vulgar en el atuendo descuidado, en las barbas largas, en la ociosidad y, sobrepasando el moralismo humanista de Sartre, en el libertinaje más desenfrenado.

Permítasenos ahora recordar al menos la polémica sobre el ateísmo, o no, de Martin Heidegger (1889). Este expuso primeramente su filosofía existencialista en la célebre obra Sein und Zeit (1927-29). Reduce el problema del ser absoluto (Sein) al de ser concreto (Dasein), que es este ser, lo que está aquí, yo mismo. Por lo tanto, el problema ontológico no es el ser (Sein), sino el ser concreto (Dasein), cuya esencia consiste en existir. Es decir: la ontología queda así reducida a un análisis existencial del Dasein por el método fenomenológico; análisis de todas las posibilidades que este Dasein realiza en todos y cada uno de los momentos de su existencia. Según nota muy bien F. Sciacca, "el método fenomenológico es el único posible para esta ontología, que es en el fondo una fenomenología, descripción de los distintos modos del Dasein en los que el ser es sorprendido y fuera de los cuales es in-existente" ${ }^{28}$. Reduciendo el problema del ser a una pura fenomenología, no hay cabida para una ontología o metafísica propiamente tal; de ahí que, después de tantós años, no haya aparecido aún

26 C. FABRo, R. MASI, etc., El pecadio en la filosofía modierna. Rialp, Madrid 1963, 237; cfr. C. FABRo, El problema del existencialismo, 128-151.

27 Cifr. A. de WAELHENs, Une philosopihie de l'ambigüité: L'existentialisme de Maurice Merleau-Ponty (Bibliotheque Philosophique de Louvain), Lrouvain 1951, IV-408; R. KwANT, "La filosofía di Maurice Merleau-Ponty": Augustinianum 1 (1961) 504-532.

28 F. ScIaCCA, La filosofía oggi, Milano 1952, I, 276; A. de WaELhens, La philosophie de Martin Heidegger" (Bibliotheque Philosophique de Louvain), Louvain, 4. ${ }^{\mathrm{a}}$ ed., $1955,380$. 
la segunda parte de Sein und Zeit, prometida por el mismo Heidegger con el título inverso de Zeit und Sein, sencillamente porque no puede ser escrita ${ }^{29}$.

Esta fenomenología del Dasein (que es el hombre concreto) pone a la muerte como la única finalidad y fin del mismo. La muerte es el constitutivo de la vida. No es que la existencia precipite en la nada, como si una fuerza omnipotente, ciega e inerte la destruyese: la muerte no viene de fuera a aniquilar el ser de la existencia, sino que coincide con el ser mismo de la existencia. Por eso ser en el mundo (in-der-Welt-sein) es ser para la muerte. Ser para el fin (Sein zum Ende) es igual a ser para la nada (Sein zum Nichts) y a ser para la muerte (Sein zum Tode). Ante esta metafísica de la nada, Sartre incluyó a Heidegger entre los ateos, y éste se defendió enérgicamente en su Carta sobre el Humanismo ${ }^{30}$, afirmando que el Dasein humano en cuanto es-en-el-mundo (in-der-Weltsein) no puede aún encontrar a Dios, pero que esto no significa negar a Dios. Heidegger nos hablará mucho de la dimensión de lo sacro (das Heilige) y de la divinidad como de la cuarta componente, -con la tierra, el cielo y los mortales-, de lo que forma la cuaternidad (das Geviert) del ser humano, el cual queda así configurado como un "permanecer ante Dios" 31.

Sin embargo, teniendo en cuenta la negación heideggeriana de la ontología, varios autores le acusan muy duramente de ateísmo real, puesto que si la nada y el ser se identifican, no hay lugar para la trascendencia ${ }^{32}$. Otros lo juzgan con más benevolencia y conceden a su filosofía una cierta posibilidad de apertura a la trascendencia ${ }^{33}$. Tal vez Heidegger, más bien que un ateo positivo, sea un filósofo agnóstico, puesto que para él, según nos advierte $H$. Urs von Balthasar, "una metafísica cristiana es algo que encierra contradicción, porque para quien conoce ya a Dios no puede constituir sinceramente un problema el misterio del ser" 34 .

29 Cfr. A. de WaElhens, O. c., 365.

30 Brief über Humanismus, Berna 1947.

31 Bauen, Wohnen, Denken, Darmstädter Gespräch 1951, Darmstadt 1952, 75 ss.; Das Ding, conferencias puiblicadas en el volumen Gestalt und Gedanke, Mónaco 1951, 128 ss.

32 Cfr. F. SCIACCA, La filosofia oggi, I, 29.0-291; G. de NAPOLI, Essere et Veritá in S. Agostino e Heidegger (Atti del Congresso Italiano di Filosofia Agostiniana. Roma, 20-23 ott. 1954), Tolentino 1956, 287-296; C. FABRo, Esistenziar lismo: Dizionario di Teología Morale, Milano 1954, 495; etc.

33 Cfr. J. Lotz, S. J., "Sein und Existenz in der Existenzphilosophie und in der Sicholastik": Gregorianum 40 (1959) 401-466; cfr. 406-413; V. VYCINAS, Earth and Gods. An Introduction to the Philosopihy of Martin Heidegger, The Hage 1961, 328.

34 H. U. von BALTHASAR, "El encuentro con Dios' en el mundo de hoy": Concitium n. 6 (junio 1965) 30 . 


\section{El ATEÍSMO MODERNO Y LA TEOLOGÍA CRISTIANA.}

Ya hemos visto cómo el ateísmo moderno implica un desarraigo de la teología en pro de una antropología o humanismo de carácter científico, político o moral. El problema de Dios no les preocupa, o al menos así lo afirman en sus filosofías. El ateísmo es ya un postulado del que es preciso partir para encontrar al hombre en sí, tal còmo es en su ser y en sus posibilidades y limitaciones. El hombre, dicen, no tiene necesidad de Dios; él mismo debe resolver sus problemas libremente con la investigación científica, con el trabajo que transforma al mundo, aceptándose tal como es, sin dependencia de ningún ser absoluto, sin sentimientos de culpabilidad o de pecado y con una ética que proviene únicamente de las contingencias sociales.

Ante este panorama desconsolador cabe preguntarse: ¿Será posible encontrar en este ateísmo de desarraigo algún aspecto positivo, que haga posible el diálogo con el cristianismo? ¿Podrá este ateísmo albergar en su seno algún elemento de verdad, que nos ponga ante la vista una deficiencia por nuestra parte y aporte un elemento positivo a nuestra teología y a nuestra moral? Muchos teólogos cristianos, abiertos a la mentalidad y a las inquietudes del hombre moderno, responden afirmativamente. Con esto creen, y con razón, poder contribuir a devolver a su pureza la tradición bíblico-teológica del cristianismo. Nó se hacen ilusiones, y las no lejanas conversaciones de Salzburg entre católicos y marxistas, así como algunas publicaciones de última hora indican que los frutos son muy escasos y las exigencias de base para el diálogo muy penumbrosas por parte de los ateos. Y sin embargo el Concilio Vaticano II desea ardientemente este diálogo, cuando dice: "La Iglesia, aunque rechaza en forma absoluta el ateísmo, reconoce sinceramente que todos los hombres, creyentes y no creyentes, deben colaborar en la edificación de este mundo, en el que viven en común. Esto requiere necesariamente un prudente y sincero diálogo. Lamenta, pues, la Iglesia la discriminación entre creyentes y no creyentes que algunas autoridades políticas, negando los derechos fundamentales de la persona humana, establecen injustamente. Pide para los creyentes libertad activa para que puedan levantar en este mundo también un templo a Dios. E invita cortésmente a los ateos a que consideren sin prejuicios el Evangelio de Cristo" 35

El mismo Concilio, después de enviar al ateísmo moderno su mensaje de trascendencia y de esperanza, nos dice: "El remedio del ateísmo hay aue buscarlo en la exposición adecuada de la doctrina y en la integridad de vida de la Iglesia y de sus miembros... Mucho contfíbuye, finalmente, a esta manifestación de la

35 Const. past. Gaudium et spes..., 21, BAC, 236. 
presencia de Dios el amor fraterno de los fieles, que con espíritu unánime colaboran en la fe del Evangelio y se alzan como signo de unidad" ${ }^{36}$. Esto nos lleva de la mano a hacer algunas consideraciones teológicas atendiendo a los postulados del ateísmo moderno en lo que puedan tener, al menos indirectamente, de positivo para nosotros.

a) PuRIFicaCión del CONCEPto DE Dios.-Tanto los errores como las herejías han desempeñado siempre un papel purificador en la historia del cristianismo. Con sus negaciones o desequilibrios doctrinales han sido una llamada; un incentivo para que la Iglesia exponga cada vez con más claridad los tesoros de las verdades reveladas y subsane con energía las deficiencias humanas de sus miembros.

Pues bien, el ateísmo moderno bajo cualquiera de sus formas nos vuelve a decir que es preciso purificar el concepto de Dios, superando ese matiz antropomórfico que penetra sin sentir en el plano de nuestras ideas. El hombre tiende siempre a revestir su concepto de Dios con ciertas representaciones inadecuadas, fruto de su finitud e imaginación, que no responden a los atributos infinitos de Dios. Es muy elocuente a este respecto la célebre frase de Voltaire: "Si Dios ha creado al hombre a su imagen, el hombre se lo ha pagado bien" 37 .

Es preciso purificar el concepto de Dios, poniendo nuevamente de relieve la filosofía y la teología negativas tan enraizadas en la mejor tradición bíblicopatrísticas. San Agustín nos dirá con frase lapidaria que "Dios es inefable; y es más fácil para nosotros decir qué no es, que qué es" 38 ; de aquí los atributos expresados en forma negativa, aunque impliquen la realidad absoluta: inefable (imposible de expresar), inmenso (sin medida), infinito (sin límites), incomprensible (no se puede comprender), etc. A este respecto, hacemos nuestras las palabras recientes de $\mathrm{H}$. U. von Balthasar: "La historia cristiana del espíritu en todos sus momentos culminantes ha colocado el conocimiento más profundo de la Biblia acerca de Dios ante el fuego de la crítica del conocimiento metafísico sobre el misterio del ser. Si comprebendis, non est Deus, advierte Agustín junto con toda la Patrística griega, como también Gregorio Magno al igual que la tradición de Dionisio Areopagita, recogida una y otra vez a lo largo de toda la Edad Media latina hasta el Cusano" 39.

36 Ibid., 21, BAC', 235-2:36.

37 Cit. por J. LACRoIX, O. c., 57.

38 Deus ineffabilis est; facilius dicimus quid non sit, quam quid sit (In Ps. 85, PL. 37, 1.090; Io. tr. 23, PL. 35, 1.588; etc.). Cfr. W. P. ToLLeY, The Ided of God in the Philosophy of St. Augustine, New York 1930; S. J. GrabowsKI, The All-Present God. A Study in St. Augustine, St. Louis-London 1954, 49-60 (abundante documentación patrística).

39 H. U. von BaLTHASAR, "El encuentro con Dios en el mundo actual": Concilium n. ${ }^{\circ} 6$ (junio 1965) 31 . 
Esta incomprensibilidad (no incognoscibilidad, como aun hoy algunos parecen confundir) de Dios nos obliga a replantear la teología natural de acuerdo con las exigencias actuales. Los argumentos metafísicos, científicos y morales para demostrar la existencia de Dios han de ser expuestos de tal modo que no se quebrante el misterio del Ser trascendente. Sin menoscabo de la doctrina bíblicopatrística definida por el Vaticano I sobre la posibilidad de conocer a Dios por la sola luz de la razón natural, es preciso que ese Absoluto, que nos explica el origen de los seres contingentes, de las ideas eternas y de la ley moral y que colma la angustia existencial del hombre "arrojado en el mundo" al saberse dependiente del Creador, no venga a profanar en modo alguno el misterio de Dios. Este misterio, la vida divina, misteriosa y fecunda, el Dios-Amor que da el ser a todo cuanto existe y que es el Padre amoroso del hombre, este misterio sólo puede desvelárnoslo plenamente $l_{a} f e$, la revelación benignamente hecha por Dios al hombre y coronada con el misterio aún más inefable de la encarnación de su propio Hijo. No podemos entrar aquí en un análisis detallado, pero toda esta problemática, avalada por la historia real del pensamiento humano, nos acerca más y más al principio clásico de San Agustín: Crede ut intelligas". Esta frontera entre la filosofía y la teología, no siempre debidamente respetadas por el cristianismo, crea problemas arduos de los cuales es muy difícil salir airosos ${ }^{40}$. En una palabra; la razón que, iluminada ya por la fe, se sumerge gustosa en las argumentaciones filosóficas acerca de Dios, debe estar muy apercibida para no tratar de imponer al no creyente, en nombre del puro raciocinio, ciertas verdades que ella lleva incrustadas en su entraña únicamente en virtud de su fe.

b) El mensaje agustiniano del Concilio Vaticano II.-En íntima conexión con el tema anterior, nos place recordar aquí el eterno mensaje agustiniano de trascendencia, que el Concilio Vaticano II envía a todos los ateos modernos: "La Iglesia sabe perfectamente que su mensaje está de acuerdo con los deseos más profundos del corazón humano, cuando reivindica la dignidad de la vocación del hombre, devolviendo la esperanza a quienes desesperan ya de sus destinos más altos. Su mensaje, lejos de empequeñecer al hombre, difunde luz, vida y libertad para el progresơ humano. Lo único que puede llenar el corazón del hombre es aquello de "nos hiciste, Señor, pará ti, y nuestro corazón está inquieto hasta que descanse en ti" 41 .

40 H. U. von BALTHASAR tiene acerca de esto observaciones muy precisas y muy duras en el art. cit., 31-33 y 40-41. También es interesante el artículo de J. B. MeTz, "La incredulidad como problema teológico": Concilium n. 6 (junio 1965) 63-83; habla de la "incredulidad del creyente" inserta en la oscuridad de la fe como acto existencial, y cómo la intersubjetividad, es decir, la comunidad de la Iglesia creyente ayuda a superar esta incredulidad. 661.

41 Const. past. Gaudium et spes..., 21, BAC, 237; Confes. I, 1, 1, PL. 32, 
Hoy día nos parece ya anacrónico el empeñarse en calificar a este argumento agustiniano, que fluye a través de toda su obra, con el débil y confuso título de eudemonológico. Los autores, que no perciben en esa inquietud del Hiponense su carácter radicalmente ontológico, están haciendo muy malos servicios a San Agustín y a la causa cristiana. Así lo afirma con mucha razón el célebre teólogo $\mathrm{H}$. de Lubac en una obra reciente ${ }^{42}$.

En otra ocasión analizaremos esto con más detención. Por ahora baste recordar que se trata de una inquietud ontológica, incrustada en el realismo del espíritu, en su conocer y amar radicales ${ }^{43}$. El separar esta inquietud radical del argumento agustiniano poco felizmente llamado ideológico, indica una idea muy extraña y muy pobre de la filosofía de San Agustín. Es preciso superar el psicologismo de que se lo ha revestido en muchas publicaciones. Todo ese mundo interior, radicalmente ordenado a la trascendencia, y que tan acertadamente llama San Agustín memoria de sí y memoria de Dios ${ }^{44}$, aflora a la conciencia por la reflexión y hace de la inquietud ontológica una inquieud consciente y sentida, lanzada inexorablemente a la búsqueda de su plenitud verdadera y única, Dios.

$\mathrm{Y}$ este es el mensaje eterno de San Agustín, que tiene una rara vigencia ante el fenómeno del ateísmo contemporáneo, especialmente el de tipo existencialista ${ }^{45}$. Porque, a pesar de todas las afirmaciones de sus corifeos, no se puede menos de constatar que esa inquietud, esa angustia, esa inestabilidad vital que los invade y atormenta, reviste siempre un carácter netamente religioso, si no cristiano ${ }^{46}$. El análisis profundo y matizado que hacen de esa inquietud, aunque en realidad no sobrepase el plano fenomenológico, nos lleva de la mano a contemplar esa inestabilidad y ese relativismo con la ontología vital agustiniana, hambrienta del absoluto, inmanente y trascendente a la vez. A este propósito, bien podemos universalizar la interesante observación del $\mathrm{P}$. Kwant con respecto a la

42 On ne lui rend pas justice quand on n'accorde qu'une portée tout empirique - a moins qu'on n'y dénonce quelque "xomanticisme" - á la phrase célèbre des Confessions: Fecisti nos ad te, Deus, et inquietum... Les theologiens medievaux lui reconnesisaient une autre portée (H. de LuBAC, Le mystere du surnaturel; Aubier; Parísi 1965, 9,2).

43 Cifr. F. CAYRÉ, Dieu present dans la vie de l'esprit, París 1951; ID. Le realisme de saint Augustin (Atti del Congresiso Agostiniano di Filosofia Agostiniana. Roma, 20-23 ott. 1954), Tolentino 1956, 354-363.

44 Cfr. L. Cilleruelo, O. S. A., "La memoria sui": Giomale di metafísiça 9 (1954) 478-492; ID. "La "memoria Dei" según S. Aguistín": Augustinus ma gisiter (Congres. Internat. Augustin.), París 1954, I, 499-509; ID. "Por qué "memoria" Dei": Revue des etudes augustiniennes 10 (1964) 289-294; J. MoRÁN, O. S. A., "Hacia una comprensión de la "memoria Dei" según San Agustín": Augustiniana 10 (1960) 83-110.

45 Cfr. R. FlóREz, O. S. A., "La significación del ateísmo según San Agustín": Religión y cultura 1 (1956) 83-110.

46 Cfr. A. de WEALHens, La philosophie de Martin Heidegger, Louvain," $4 .^{a}$ ed., 1955, 358, recogiendo las afirmaciones de J. HERSCH, K. LöWITH, E. LEVINAS, etc. 
filosofía de Merleau-Ponty: "El estudio de la filosofía de Merleau-Ponty es utilísimo para nosotros, porque nos hace conscientes del verdadero núcleo de la filosofía cristiana y, además, de las dificultades que le opone la conciencia moderna. El hombre, materia penetrada por el hálito de Dios, es al mismó tiempo absoluto y relativo; precisamente la unidad de estos dos aspectos es lo que caracteriza al hombre. De ahí que cada época tenga su manera propia de experimentar lo absoluto y la relatividad. En la filosofía de Merleau-Ponty encontramos la expresión de la experiencia de la relatividad según anida en el hombre moderno, y por lo mismo en el diálogo con esta filosofía podemos aprender de qué modo hemos de afirmar lo absoluto en los tiempos modernos, qué argumentos están superados y cuáles conservan aún su eficacia. El que no pasa por la con ciencia de la relatividad, no puede afirmar lo absoluto del modo debido" ${ }^{47}$.

c) El hUMÁNismo ATEO Y El CRISTIANISMo.-El ateísmo moderno en su parte positiva o bumanismo tiene también su mensaje para los cristianos. No es un mensaje nuevo, sino más bien una llamada de alerta para que revitalicemos el gran mandamiento del amor fraterno, tan insistentemente proclamado por Cristo y por los Apóstoles, en especial por el discípulo amado, San Juan, como la teofanía o manifestación de Dios en la tierra. Ya nos lo recuerda el mismo Concilio Vaticano II, cuando dice: "Mucho contribuye, finalmente, a esta manifestación de la presencia de Dios el amor fraterno de los fieles, que con espíritu unánime colaboran en la fe del Evangelio y se alzan como signo de unidad" 48 .

El humanismo ateo nos recuerda, en primer lugar, que es preciso aceptar al hombre tal como es en las condiciones actuales, con su finitud, su responsabilidad y su destino que habrá de cumplir dolorosamente en esta tierra. "El mayor mérito del ateísmo actual, dice J. Lacroix, es el de efectuar un prodigioso desbaste intelectual de la humanidad rechazando toda idolatría: no quiere hacer del hombre un dios, sino aceptar íntegramente su humanidad y asumirla por entero" 49 . Es preciso dar la debida importancia a la responsabilidad humana para forjar su destino terreno, exaltar la función de la ciencia y del trabajo para la transformación del mundo. Es decir: el providencialismo de los cristianos no debe destruir los valores humańos, sino perfeccionarlos, resacralizarlos, añadiendo a su relatividad y contingencia la categoría superhumana. El Concilio Vaticano II nos ofrece en este sentido un inmenso panorama cristiano-humanista, que debe guiar en adelante la llamada teología de las realidades terrenas. Tan nefasto es el naturalismo desnudo, como el misticismo mal entendido o el angelismo irreal

47 R. KWANT, O. S. A., "La filosiofía de Maurice Merleau-Pontty": Augustinianum 1 (1961) 532.

48 Const. past. Gaudium et spes..., 21, BAC, 236.

49 J. LACRoIX, El sentido del ateísmo moderno, Barcelona 1964, 65. 
y opuesto a los designios de Dios. $\mathrm{Y}$ en realidad la verdadera postura evangélica, que evidentemente excluye todo humanismo puro, desconectado de lo divino, nos enseña a tomar al hombre tal como es, libre y responsable de sus actos, pecador e indigente, laborioso y orante, caminando por la senda de su destino entre victorias y caídas, en una palabra, un hombre humano con un destino divino. Un autor moderno ha llegado a exclamar: "Si les estoy agradecido a mis amigos ateos, es porque me han enseñado a no hacer trampas. El hombre no es un dios: no es esto toda la verdad, pero sí la primera y la más indispensable. Una crítica radical de todos los absolutos humanos era sin duda necesaria para desprender el único verdadero. Demasiados creyentes han querido jugar a la divinidad o ponerse en su lugar. No era inútil depurar nuestras representaciones, para asegurar mejor nuestra intención" 50 .

En segundo lugar, el ateísmo moderno, con la importancia que atribuye al amor mutuo de los hombres, a la intersubjetividad humana, nos recuerda a los cristianos la necesidad de revitalizar el gran mandamiento del amor al prójimo, como la verdadera teofanía del amor del hombre a Dios. Ya nos lo dijo claramente San Juan: "Si alguno dijere: Amo a Dios, pero aborrece a su hermano, miente. Pues el que no ama a su hermano, a quien ve, no es posible que ame a Dios, a quien no ve. $\mathrm{Y}$ nosotros tenemos de $\mathrm{El}$ este precepto: que quien ama a Dios, ame también a su hermano". (I J., 4, 20-21). No negamos las limitaciones, pero es preciso admitir, como ya vimos antes, que algunos de los corifeos del ateísmo sistemático contemporáneo, como Feuerbach, ensalzaron de un modo extraordinario el sentido del amor social como solución de los problemas más acuciantes de la humanidad dolorida. Las organizaciones comunistas nos dan ejemplo de un heroismo auténtico, y con frecuencia sin recompensa, en pro de las comunidades trabajadoras. Filósofos existencialistas, como Sartre, volverán a encontrar un sentido a la vida en función de las contingencias sociales, que los llevan a formar parte o al menos a simpatizar con el marxismo. En una palabra, también el ateísmo moderno tiene, a pesar de sus limitaciones abismales, un papel purificador y un mensaje positivo para los cristianos de hoy. No sé porqué; pero de hecho la conversación con los ateos que he encontrado por esos mundos me ha producido siempre un impacto de respeto y un hondo sentimiento del misterio humano que se desgaja, no sin angustia, del misterio de Dios.

No quisiera terminar estas breves consideraciones sin recordar al menos un grande peligro de este humanismo ateo para los menos apercibidos. Es el naturalismo cerrado, que brota como un fruto maduro de esa moral sin pecado. Un hedonismo sin límites se ha infiltrado en la sociedad moderna al perder el sentido de la trascendencia y de la vida futura. El paraíso marxista en la tierra se

50 J. LACROIX, O. c., 66. 
ha revelado, como era lógico, una bella utopía, pero ha ganado muchos adeptos, incluso entre los cristianos. Estas convulsiones y desasosiegos que se notan hoy por doquier, incluso en los ambientes más escogidos de la Iglesia, denotan sin duda el influjo de esas corrientes de signo naturalista, y casi inconscientemente se rebelan contra la plena realidad del cristianismo, que es esencialmente un misterio de gracia y de redención. La Cruz vuelve a convertirse en signo de escándalo y de necedad para los hombres, como decía ya San Pablo (1 Cor. 1, 23). Y, sin embargo, la cruz, llevada con amor en pos de Jesús, será siempre el camino de la salvación: "El que no toma su cruz y me sigue, no es digno de mí" (Mt. 10, 38).

P. Argimiro Turrado, O. S. A. 